\title{
Fraser Syndrome, Evaluation of the Laryngeal and Voice Charac- teristics: A Case Report
}

\author{
Seyed Abolfazl Tohidast, PhD and Banafshe Mansuri, PhD* \\ Assistant Professor, Department of Speech Therapy, Neuromuscular Rehabilitation Research Center, \\ Semnan University of Medical Sciences, Semnan, Iran
}

*Corresponding author: Banafshe Mansuri, PhD, Assistant Professor, Department of Speech Therapy, Neuromuscular Rehabilitation Research Center, Semnan University of Medical Sciences, Basij Blvd, Semnan, 3513138111, Iran, Tel: $+989134300401$

\begin{abstract}
Introduction: Fraser syndrome is one of the rare congenital anomalies occurring when fingers or toes, and eyelid formation fail to separate during pregnancy. The purpose of this paper is to report the results of laryngeal and voice evaluation in a patient with Fraser syndrome.

Case description: The case is an eleven-years-old girl with Fraser syndrome who underwent laryngeal examination with laryngoscopy and also auditory-perceptual and acoustic voice characteristics evaluations. The results of the laryngoscopy showed that the vocal folds are webbed and most of the anterior-posterior part of the vocal folds is connected. Only one cleft on the posterior part of the larynx is exist which is the child's breathe performed through it. The results of the auditory-perceptual evaluation of the voice using the GRBAS scale showed that the grade of voice disorder, asthenicity, and strain of the child's voice are very severe. Also, the results of the acoustic voice evaluations showed that the acoustic characteristics of the child's voice are outside of the normal range, and most of the time, the child's speech is voiceless, and the speech produced by the person is like whispering.

Conclusions: This report indicated that laryngeal web in Fraser syndrome can cause most negative effects on the auditory-perceptual and acoustic characteristics of the person's voice. Therefore, these patients need to be evaluated by visual assessment of the larynx, auditory-perceptual and acoustic assessment of voice.
\end{abstract}

\section{Keywords}

Fraser syndrome, Syndactyly, Laryngeal web, Acoustic assessment, Laryngoscopy

\section{Introduction}

Fraser syndrome is one of the rare congenital anomalies occurring when fingers or toes, and eyelid formation fail to separate during pregnancy [1]. So far, few cases (less than 200 cases) with this anomaly have been reported $[2,3]$. Syndactyly syndrome that characterized by webbing of fingers and toes are more likely than Fraser syndrome, however, webbed fingers or toes may be present in both Fraser and syndactyly syndromes $[1,4]$. The incidence rate of syndactyly syndrome is not completely clear but is estimated at about 1 per 2000 or 3000 live births [4]. In these two genetic disorders, during normal fetal growth, the fingers have a web between each set of digits prior to the apoptosis process, the separation of the finger skin and development of interdigital folds. The separation of the fingers and the development of interdigital folds are usually terminated by end of the sixth embryo week [4]. These conditions are normal in some mammals, such as kangaroos, but are abnormal in humans [5]. The syndactyly in Fraser syndrome can be simple or complex. In simple mode, adjacent fingers or toes are joined by soft tissue. In complex mode, the bones of adjacent digits are interconnected. The syndrome can occur in either a complete or an incomplete form. In the complete form, the union of fingers is extended to end of fingertips, but in the incomplete form, only part of the fingers is fused. Complex syndactyly occurs as part of a syndrome (such as Apert syndrome) and typically involves many fingers $[4,6-8]$. This condition in fingers and toes may occur in all parts of the body that require interfusion to be elimi- 
nated during pregnancy [8-10]. These conditions can be seen for fingers and toes, eyelids or even vocal folds in Fraser syndrome [1], however, vocal folds involvement is less common than involvement of the fingers, toes, and eyes [9]. The presence of this syndrome in vocal folds develops vocal fold web, also called as glottis web $[9,10]$.

The glottic web develops between two vocal folds, which can cover part or all of the length of the vocal folds and impair the normal vibration and functioning of the vocal folds, causing changes in vocalization and voice quality. The glottic web can be either congenital or acquired. The congenital type occurs at birth and usually involves two thirds of vocal folds resulting from joined membranes of the glottis during fetal growth. In this case, there is stridor noise, high-pitched breath voice and high frequency crying [11]. Respiratory problems and stridor can lead to the detection of congenital glottic web that occurred as a result of deformities and problems during pregnancy. During embryonic development, the vestibule and the laryngeal lumen are simultaneously formed from lamina propria, which joined the primordial epiglottis and arytenoid cartilages. Reestablishment of the upper and lower airways of the glottis eventually involves the separation of this connective tissue. Problem in the process of the separation of this connective tissue develops the web in various sites. Early detection is more likely to occur when true vocal folds and glottis are specifically involved in the web. The glottic web problem may not be diagnosed for long [12]. The acquired glottic webs can occur as a result of bilateral hits the margins of the vocal folds. In fact, any event that damages the mucosal surface of the vocal folds can be a primary reason for developing the webs. Due to the proximity of the two vocal folds to the anterior juncture, damage and prolonged infections in this area may cause a thin inter-membrane. Bilateral vocal cord surgeries to remove the nodule or papilloma can develop the webs. Laryngeal surgeries are the most common cause for the formation of the webs [11].

As noted earlier, the Fraser syndrome is one of the congenital disorders that can lead to glottic web, though the occurrence of glottic web is very rare in these patients [9]. Therefore, limited studies to date have investigated glottic web in the patients with Fraser syndrome and syndactyly. Izadi, et al. (2015) reported two cases of patients with Fraser syndrome, including two 11 and 12-year-old girls, both of whom were diagnosed with glottic web after airway examination. In this report, they often dealt with the surgical procedure in these two cases and did not evaluate voice assessments for patients [9]. Alvarez Neri, et al. (2017) reported a 6-month-old girl with Fraser syndrome, whose vocal cord was observed in the anterior two-thirds of vocal folds at laryngeal examination. To the best of our knowledge, none of these reports referred to the acoustic and auditory-per- ceptual characteristics of the voice in these patients [10]. Therefore, the purpose of this case report is to pay more attention to the acoustic and auditory-perceptual characteristics of the voice in children with Fraser syndrome to diagnose this problem earlier if the glottic web is present and follow-up is required.

\section{Case Description}

The case was an 11-year-old girl with the Fraser syndrome. Her fingers and toes were joined, which was developed in childhood through the surgery for interfingers folds. Both eyelids were also fused to the face due to the failure to separate the connective tissue during the fetal period. Due to the need for extensive surgical procedures on her eyes, the child was referred to speech therapy for airway examination and status to be evaluated for laryngoscopy of the larynx. Visual evaluation of the larynx was performed using video laryngoscopy, and the acoustic characteristics of voice samples, including vowel sustaining and connected speech, were assessed using Praat software. Auditory-perceptual evaluation of connected speech samples was performed using the GRBAS scale. On this scale, grade of hoarseness, roughness, breathiness, asthenia and strain were assessed on a 4-point Likert scale. On this scale, the severity of the disorder is expressed in each case with a point ranging from 0 to 3 , indicating 0 as normal voice and no disturbance and 3 as severe defects in the voice. Auditory-perceptual evaluation was performed by a speech-language pathologist with over 10 years of experience in the evaluation and treatment of voice disorders. Due to the specific circumstances and blindness of the child, the laryngoscopic procedure was performed after several attempts because of poor co-operation. Laryngoscopic findings showed a glottic web extended from anterior to posterior, albeit a cleft was observed in the posterior laryngeal inlet through which the child breathed (Figure 1 and Figure 2).

After visual laryngeal examination, the speech sam-

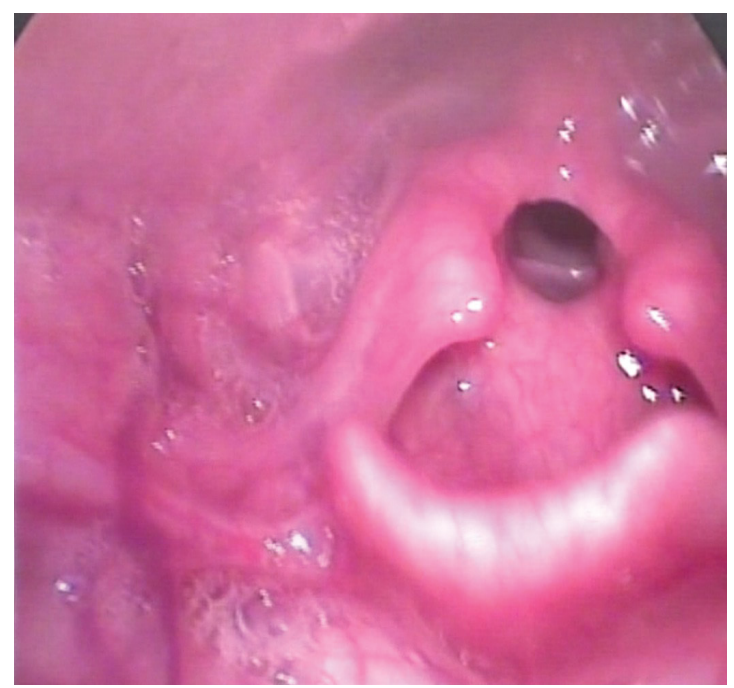

Figure 1: A photo of the patient's larynx by video laryngoscopy. 


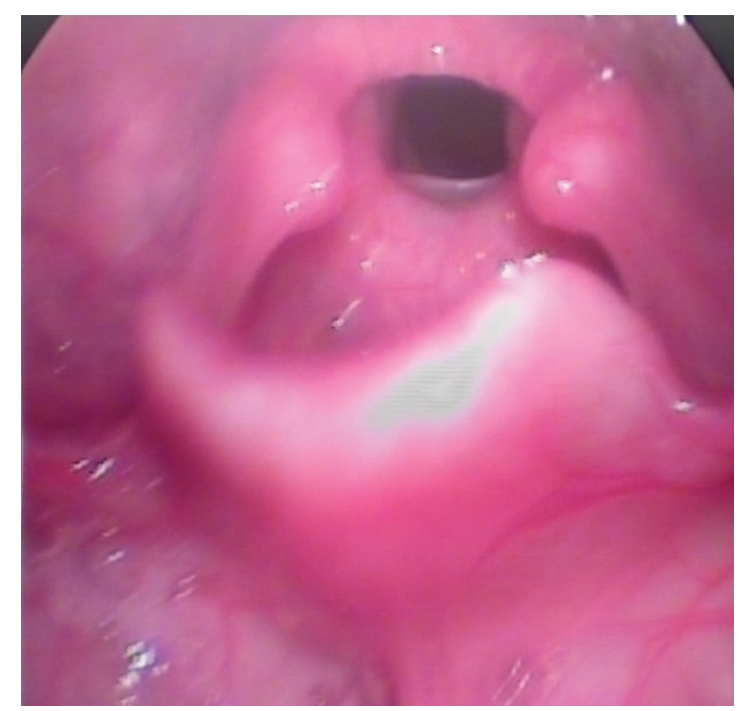

Figure 2: A photo of the patient's larynx by video laryngoscopy during breathing.

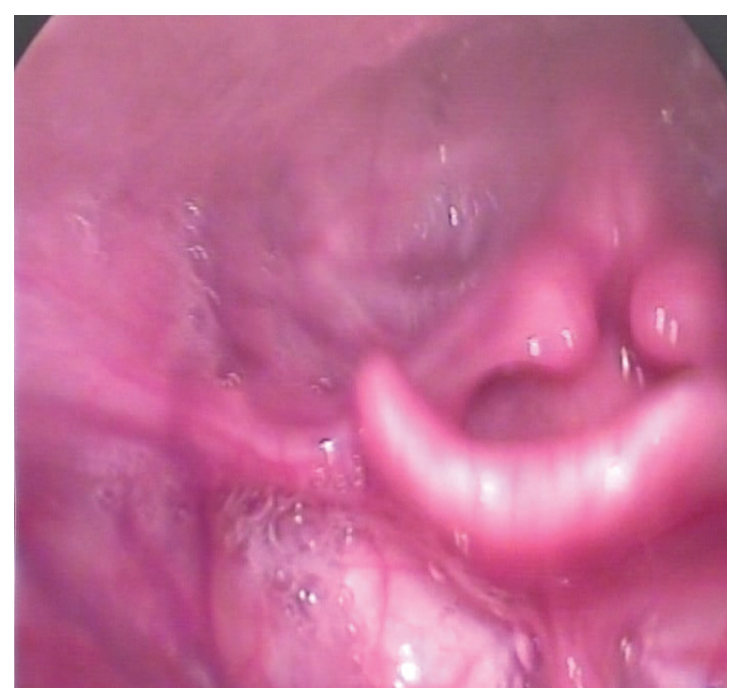

Figure 3: A photo of the patient's larynx during phonation.

Table 1: The results of acoustic assessment of voice.

\begin{tabular}{|c|c|c|c|c|c|c|c|c|}
\hline Items & $\begin{array}{l}\text { Fundamer } \\
(\mathrm{Hz})\end{array}$ & requency & Jitter $(\%)^{*}$ & & Shimmer & & $\begin{array}{l}\text { Harmonic } \\
\text { Ratio (HN }\end{array}$ & $\begin{array}{l}\text { Noise } \\
\text { (db) }\end{array}$ \\
\hline Tasks & $\begin{array}{l}\text { Reported } \\
\text { case }\end{array}$ & $\begin{array}{l}\text { Normal } \\
\text { range }\end{array}$ & $\begin{array}{l}\text { Reported } \\
\text { case }\end{array}$ & $\begin{array}{l}\text { Normal } \\
\text { range }\end{array}$ & $\begin{array}{l}\text { Reported } \\
\text { case }\end{array}$ & $\begin{array}{l}\text { Normal } \\
\text { range }\end{array}$ & $\begin{array}{l}\text { Reported } \\
\text { case }\end{array}$ & $\begin{array}{l}\text { Normal } \\
\text { range }\end{array}$ \\
\hline Vowel /a/ & 401.34 & $220-280$ & 1.52 & $<0.5$ & 15.34 & $<3$ & 11.68 & $>13$ \\
\hline Connected Speech & 372.84 & $220-280$ & - & - & - & _- & 3.93 & $>13$ \\
\hline
\end{tabular}

The jitter and shimmer are not reported in connected speech task.

Table 2: The results of auditory-perceptual assessment of voice using GRBAS.

\begin{tabular}{|c|c|c|c|c|c|}
\hline Items & Grade & Roughness & Breathiness & Asthenicity & Strain \\
\hline Score & 3 & 2 & 2 & 3 & 3 \\
\hline
\end{tabular}

GRBAS: Grade, Roughness, Breathiness, Asthenicity, Strain In GRBAS scale, 0 = normal voice, and 3 = severe impairment

ple was analyzed. Despite being blind, the child was able to communicate well through speech and had no problem with speech skills. The phonemes were well produced. Not only the voice quality was unpleasant, but also there seemed to be some problems with the vocalization system. For further investigation, the voice sample was acoustically evaluated by Praat software. The results of acoustic analysis of the voice sample taken from the child showed that very few parts of speech had vocalization and frequency, and speech had no vocalization in most cases, and the voice had no frequency, and thus a whispering state. Data on acoustic characteristics of voice during vowel sustaining and connected speech are presented in Figure 1. Based on these results, the mean baseline frequency was 401.34 and 372.84 in vowel sustaining and connected speech tasks, respectively (Table 1).

The results of the perceptual assessment of the child's connected speech using the GRBAS scale are shown in Table 2. According to the findings, the most common problem for the child's voice was the grade of hoarseness, asthenia and strain with the score of 3 (severe defect). Evidence from visual assessments of the larynx and the acoustic and auditory-perceptual characteristics of the voice showed that the glottic web made the vocal fold vibration difficult and very low and the speech of the individual more through whispering. These have made her speech intelligible despite the unpleasant voice quality. Because of the need for communication, the child is likely to use the same unpleasant voice, which is more like a whisper, to communicate (Table 2).

\section{Conclusions}

Fraser syndrome is one of the rare congenital syndromes characterized by failing the separation of membrane webs, between the parts of the body that must undergo resorption during embryonic development [4]. Since the larynx is one of the parts with membrane fusion, this syndrome may also affect the larynx and especially the vocal folds. This laryngeal disorder can cause for respiration and vocalization. The congenital glot- 
tic web is actually a condition in people with this syndrome that causes respiratory and vocalization problems $[9,10]$. As previously stated, the case reported in this study also had severe problems with vocalization and due to its vocal folds involvement. According to the results of acoustic studies of the voice, her speech had no vocalization in most cases and was similar to whispering. Therefore, this person probably overcomes this problem by using subglottic pressure and noise development in most cases, and has maintained her ability to communicate through speech (Figure 3). However, the voice created in this way has developed a connection with unpleasant and monotonous voice quality. Based on acoustic evaluations, the fundamental frequency of a child's voice sample is greater than the normal range of the fundamental frequency of girls in both vowel sustaining and connected speech [13]. The jitter and shimmer values of the child's voice, which were 1.52 and 15.34 , respectively, were much higher than the normal range, indicating a high degree of voice disturbance. The normal range for jitter is less than 0.5 and for shimmer is less than $3[12,14]$. The harmonics-to-noise ratio (HNR), given that its normal value in girls should be above 13 , was below this value in both vowel sustaining and connected speech tasks, indicating the absence of normal voice in the individual [15]. The results of auditory-perceptual voice assessment using the GRBAS scale also confirmed the results of acoustic assessments and indicated significant problems with individual voice quality. As shown in Figure 1 and Figure 2, the person was breathing through a cleft in the posterior larynx. Given that other reports of the disease did not specify the acoustic and auditory-perceptual characteristics of the voice for these patients $[9,10]$, the data in this report may be helpful in this regard, and future reports in these patients should be reviewed frequently for the acoustic and auditory-perceptual characteristics of their voice (Figure 3).

According to the reported case, the Fraser syndrome can be considered as one of the causative agents of congenital glottic web. It is suggested that children with syndactyly (webbing fingers and toes) and cryptophthalmos should be under visual assessment of the larynx to examine the presence or absence of the glottic web. In the presence of the glottic web, it is suggested that early remedies should be taken, as well as follow-up of these patients is highly essential given the development of respiratory risks by this problem. In addition, it is better to evaluate the airway of these children thoroughly for specific surgeries given the specific conditions of such patients for proper operation.

\section{Acknowledgments}

The authors would like to thank and appreciate the study case and her families for their cooperation and participation in the various stages, as well as the Speech and Language Lab staff at the School of Rehabilitation.

\section{Conflicts of Interest}

The authors declared that there are no conflicts of interest.

\section{References}

1. Barisic I, Odak L, Loane M, Garne E, Wellesley D, et al. (2013) Fraser syndrome: Epidemiological study in a European population. American Journal of Medical Genetics Part A 161: 1012-1018.

2. Slavotinek A, Tifft C (2002) Fraser syndrome and cryptophthalmos: Review of the diagnostic criteria and evidence for phenotypic modules in complex malformation syndromes. Journal of Medical Genetics 39: 623-633.

3. Mathers JD, Breen TM, Smith JH (2014) Delivery of anesthesia and complications for children with Fraser syndrome: A review of 125 anesthetics. Pediatric Anesthesia 24: 12881294.

4. Dao KD, Shin AY, Billings A, Oberg KC, Virchel EW (2004) Surgical treatment of congenital syndactyly of the hand. J Am Acad Orthop Surg 12: 39-48.

5. Malik S (2012) Syndactyly: Phenotypes, genetics and current classification. Eur J Hum Genet 20: 817-824.

6. Mondolfi PE (1983) Syndactyly of the toes. Plast Reconstr Surg 71: 212-218.

7. Miura T, Nakamura R, Suzuki M, Watanabe K (1992) Cleft hand, syndactyly and hypoplastic thumb. J Hand Surg 17: 365-370.

8. Sadler TW (2009) Langman s Medical Embryology. (11 th edn), Lippicontt Williams \& Wilkins.

9. Izadi F, Ahmadi A, Zobairy H, Bakhti S, Hirbod H, et al. (2015) Fraser syndrome with laryngeal webs: Report of two cases and a review of the literature. International Journal of Pediatric Otorhinolaryngology 79: 1959-1962.

10. Alvaréz-Neri H, Morán VF, De La Torre C, Villamor $P$, Grub JP (2017) Airway features in Fraser syndrome: Case report and literature review. International Journal of Pediatric Otorhinolaryngology Extra 18: 16-18.

11. Boone DR, McFarlane SC, Von Berg SL (2006) The voice and voice therapy. $\left(10^{\text {th }}\right.$ edn), Pearson.

12. Colton R, Casper J (2010) Understanding Voice Problems: A Physiological Perspective for Diagnosis and Treatment: Williams \& Wilkins.

13. Soltani M, Ashayeri H, Modarresi Y, Salavati M, Ghomashchi H (2014) Fundamental Frequency Changes of Persian Speakers Across the Life Span. Journal of Voice 28: 274281.

14. Mohamadi O, Sadolahi A, Ghorbani R (2011) Effects of smoking cigarette on some acoustic voice parameters and elements of speech pattern of male subjects. Koomesh 12: 253-258.

15. Verma P, Pal M, Raj A (2010) Objective acoustic analysis of voice improvement after phonosurgery. Indian Journal of Otolaryngology and Head \& Neck Surgery 62: 131-137. 